\title{
Salutogenesis Meeting Places: \\ The Global Working Group, the Center, and the Society on Salutogenesis
}

\author{
Georg F. Bauer
}

\section{Introduction}

Salutogenesis is a rapidly expanding academic field of research relevant to theory, practice, and policy (Bauer et al., 2020). This chapter presents the Society for Theory and Research on Salutogenesis (STARS). It also describes two other organizations that are closely involved with the society (Fig. 6.1):

- The Global Working Group on Salutogenesis (GWG-Sal) of the International Union for Health Promotion and Education (IUHPE).

- The Center of Salutogenesis of the University of Zürich in Switzerland (Center), which hosts and coordinates the two aforementioned groups, alongside its research activities.

We, the Editors of this handbook, extend an invitation to you to join STARS, which is transdisciplinary and open to all persons who are interested in salutogenesis. Indeed, the key message of this chapter is that your involvement in STARS will extend your professional network, open new avenues for research and publishing, and help achieve a vision of "salutogenesis for thriving societies" (see Chap. 61).

If you are working in the field of health promotion, membership in the IUHPE is also cordially invited - visit www. iuhpe.org. As an IUHPE member, you will have direct access to - and the possibility to be elected to - the GWG-Sal. Aside from its vital coordinating function as shown in Fig. 6.1, the Center is significant due to its work organizing international salutogenesis conferences and publishing material such as this handbook, available to all as a free, open-access publication due to financial support from the Center.

\section{G. F. Bauer $(\bowtie)$}

Center of Salutogenesis, Division of Public and Organizational Health, Epidemiology, Biostatistics and Prevention Institute, University of Zürich, Zürich, Switzerland

e-mail: georg.bauer@uzh.ch

\section{Society for Theory and Research on Salutogenesis (STARS)}

STARS aims to advance and promote the science of salutogenesis. These principles guide it:

- Transdisciplinary: STARS connects scholars from diverse disciplines, who share an interest in the science of salutogenesis.

- Open membership: STARS welcomes anyone with an interest in the science of salutogenesis! Having published salutogenesis articles is not a condition of membership. Students are especially welcome. Joining is easy, and it is free of charge.

- Sharing: STARS members are encouraged to announce their publications, news, and events on the STARS website, download free materials such as research questionnaires and books, join discussion groups, and participate in STARS-sponsored conferences.

At www.stars-society.org (Fig. 6.2), you can follow recent news and events on salutogenesis, get informed about recent publications on salutogenesis (including new language editions of The Hitchhiker's Guide to Salutogenesis) (Lindström \& Eriksson, 2010), learn about upcoming conferences, and interact with colleagues in the discussion forum. Further, you get free access to the Sense of Coherence (SOC) Scales, and you can freely download the classic books by Aaron Antonovsky. In the membership database, you can search for colleagues working in your country or specific subfield of salutogenesis research and can get connected to regional networks on salutogenesis.

STARS organizes regular, international conferences on salutogenesis. Recently, we added an overview of current salutogenesis research of STARS members related to the COVID-19 crisis. To become engaged in STARS, visit the website, follow us on Twitter (@stars_society), sign up for our newsletter, and become a member now 
Fig. 6.1 Salutogenesis meeting places and their relationships

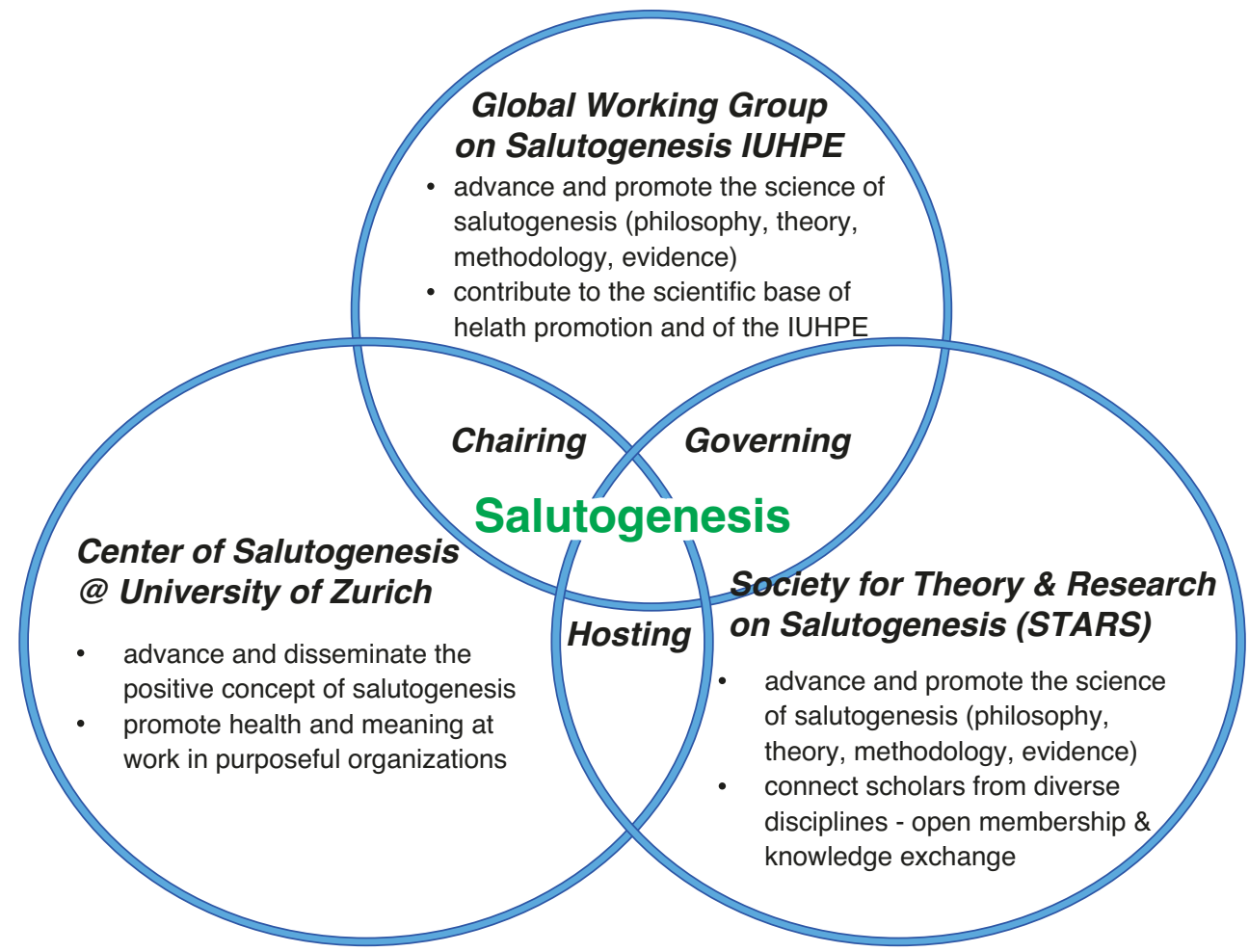

and share your perspectives and expertise. Together, we will advance our vision of "salutogenesis for thriving societies!"

\section{Global Working Group on Salutogenesis (GWG-Sal)}

GWG-Sal was established in 2007 by the IUHPE, and it has since been crucial for broadening the foundation of salutogenesis in the academic field of health promotion. Not least, the GWG-Sal initiated the first edition of The Handbook of Salutogenesis. This second edition of the Handbook is a joint effort of STARS, GWG-Sal, and the Zürich Center. These major writing projects bring together academics from across the Globe. We cordially invite readers to suggest content for, and contribute to, future editions of the handbook.

The Mission of the GWG-Sal is "to advance and promote the science of salutogenesis (philosophy, theory, methodology, evidence) and thus to contribute to the scientific base of health promotion and the IUHPE" (www.iuhpe.org/index. php/en/global-working-groups). It does this by:

- Salutogenesis agenda setting for, within and beyond, the IUHPE.

- Infusing salutogenesis in IUHPE activities.

- Engaging with key (regional) research fields and stakeholders for capacity-building regarding salutogenesis.
The GWG-Sal is an international group of more than 20 academics representing different world regions and research areas in salutogenesis. GWG-Sal elects new members from the IUHPE, seeking to include underrepresented geographical areas, emerging research themes, and experts willing to work for our mission proactively. We self-apply salutogenesis to our group through considering principles of the Ottawa Charter; assuring inclusiveness regarding regions, gender, and age; following a coherent work plan; and voluntary engagement through joyful experience. The GWG-Sal pursues the following strategies specified in regularly updated action plans:

- We meet regularly to review developments in the field of salutogenesis, health promotion and public health, and to agree on action needed to advance salutogenesis.

- We regularly contribute keynotes, symposia, and workshops to scientific conferences and seminars related to salutogenesis.

- We contribute to the written academic discourse through compilation and regular updates of The Handbook of Salutogenesis as well as through joint position papers on general advancements of salutogenesis (Bauer et al., 2020 ) and on the specific contribution of salutogenesis in times of COVID-19 and other crises (Maas et al., forthcoming).

- We promote networking and exchange of the academic community of salutogenesis through the initiation and support of the activities of STARS, including regular international conferences. 
STARS: Society for Theory And Research on Salutogenesis

\begin{tabular}{l|l|l|l|l|l|l|l|l|}
\hline \\
\hline
\end{tabular}

\title{
A transdisciplinary platform for scientific exchange on SALUTOGENESIS
}

\begin{abstract}
Welcome to the homepage of the Society for Theory And Research on Salutogenesis (STARS)! The Society was founded by the Global Working Group (GWG) on Salutogenesis of the International Union for Health Promotion and Education (IUHPE) in 2017. Its overarching aim is to advance and promote the science of Salutogenesis by connecting research and researches around the globe.
\end{abstract}

On this website, you can find more information about STARS, follow recent news and events on Salutogenesis, and learn about upcoming conferences. Also, you can become a member of the STARS. Membership is entirely free, and there are no preconditions, such as having published articles on Salutogenesis. Members have free access to the Sense of Coherence (SOC) Scales and can follow and contribute to ongoing discussions about Salutogenesis on the forum.

We invite everyone to download the freely accessible classic books by Aaron Antonovsky and the Handbook of Salutogenesis, published by the GWG in 2017, which provides an in-depth overview of the most recent scientific developments and practical applications of Salutogenesis in its broadest sense.

The Center of Salutogenesis at the University of Zurich in Switzerland is coordinating the STARS Society website. We invite all of you to share publications or any other work and updates on Salutogenesis, thereby advancing and promoting the science of Salutogenesis in a comprehensible, manageable, and meaningful way.

You can follow STARS on Twitter to learn about recently published studies on Salutogenesis and get regular updates related to STARS.

\section{The Latest News and Events}

Fig. 6.2 The STARS website (www.stars-society.org)

- We are working to connect salutogenesis-related research initiatives across Europe and beyond to advance our vision of coherence-rich, thriving societies that master societal challenges in a humanistic way. Such challenges include pandemics, racism, rising inequalities, eroding democracies, and planetary health. Our goal is to investigate the role of coherence and value systems in the development of new equilibria of individuals, groups, organizations, and societies in the face of crisis.

\section{Center of Salutogenesis, University of Zürich}

The first coordinating center for salutogenesis was organized and run by Bengt Lindström in the period 2005-2012, at the Folkhalsan Health Promotion Research Center in Helsinki, Finland (another important center of activity on salutogenesis, established by Monica Eriksson and Bengt Lindström, serves Swedish researchers and is located at University West in Sweden).
In 2012, the international coordinating center moved from Helsinki to the Norwegian University of Science and Technology in Trondheim, Norway, where Lindström held the first-ever Professorship in Salutogenesis.

On Lindström's retirement in 2016, Georg Bauer initiated to take over the international coordinating center role. In 2017, the President of the University of Zürich formally launched the Center of Salutogenesis, financially supported by a philanthropic foundation. The Center aims to advance and disseminate the powerful, positive concept of salutogenesis in the fields of public health, health promotion, economics, and beyond. Our research systematically applies salutogenesis to the specific context of working life and organizations - facilitating the testing and advancement of the general theory of salutogenesis. Currently, the Center focuses on the following research and development themes:

- «Stress reduction + Meaning-making»: Employees' proactive, resource-oriented crafting of the dynamic working and private life to reduce stress and to create meaningfulness 
- «Salutogenic organizational change»: Leader and team development to improve working conditions, collaboration, and meaningfulness

- «Purposeful organizations»: Mind map and participatory approaches to creating purposeful organizations that make a difference for society

- «Positive health»: Developing concepts and indicators of positive health at work and in organizations (happiness, well-being, meaningfulness, and purpose)

\section{Conclusion}

Because you are reading this chapter, I know you have a serious interest in salutogenesis! You are welcome and needed as an active participant in the salutogenesis meeting places described in this chapter. Join STARS for free, for access to a global salutogenesis network, research materials such as questionnaires, books by Aaron Antonovsky and other scholars, involvement in discussion groups, and news about salutogenesis.

\section{References}

Bauer, G. F., Roy, M., Bakibinga, P., Contu, P., Downe, S., Eriksson, M., ... Mana, A. (2020). Future directions for the concept of salutogenesis: A position article. Health Promotion International, 35(2), 187-195.

Lindström, B., \& Eriksson M. (2010). The hitchhiker's guide to salutogenesis: Salutogenic pathways to health promotion. Folkhälsan research center, Health Promotion Research.

Maass, R., Meier Magistretti C., Roy M., Mana A., Shorey S., Vaandrager V., Sagy S., Antonovsky A., Saboga-Nunes L., Juvinya Canal D., Contu P., Bakibinga P., Lindström B., Bauer G.F. (under review). Salutogenesis: Promoting health during the COVID-19 pandemic and beyond.

Open Access This chapter is licensed under the terms of the Creative Commons Attribution 4.0 International License (http://creativecommons. org/licenses/by/4.0/), which permits use, sharing, adaptation, distribution and reproduction in any medium or format, as long as you give appropriate credit to the original author(s) and the source, provide a link to the Creative Commons license and indicate if changes were made.

The images or other third party material in this chapter are included in the chapter's Creative Commons license, unless indicated otherwise in a credit line to the material. If material is not included in the chapter's Creative Commons license and your intended use is not permitted by statutory regulation or exceeds the permitted use, you will need to obtain permission directly from the copyright holder. 